\title{
Effect of Dinitrophenol on the Interaction between Myosin and Nucleotides ${ }^{1}$
}

\author{
Jacob J. Blum ${ }^{2}$ and E. Felauer \\ From the Mental Health Research Institute and Department of Biological Chemistry \\ University of Michigan, Ann Arbor, Michigan
}

Received November 13, 1958

\section{INTRODUCTION}

Webster (1) first noticed that 2,4-dinitrophenol increased the ATPase ${ }^{3}$ activity of myosin. Attention was focused on this observation by the work of Greville and Needham (2) and Chappell and Perry (3), who showed that under certain conditions DNP accelerated the ATPase activity of myosin A, myosin B, and myofibrils, whereas the ITPase activity was inhibited. They noted the similarity between their results and the known effects of DNP on mitochondrial ATPase activity $(4,5)$. Upon examination of these findings, it occurred to us that with the aid of a kinetic scheme already used to interpret certain enzymic and light-scattering studies on myosin (6), one could explain in a qualitative fashion some of the observed effects of DNP on ATPase and ITPase activity. If these ideas were relevant, then it was also of interest to examine the effects of DNP on some other nucleotides, and to attempt to correlate the enzymic data with concomitant contractile data. Such studies might shed more light not only on the nature of the enzymic site and its mode of interaction with the substrate molecule, but also might be of value in elucidating the nature of the mechanochemical coupling.

${ }^{1}$ This research was supported by Grant RG 4917 from the National Institutes of Health.

${ }^{2}$ Present address: Gerontology Section, Baltimore City Hospitals, Baltimore, Md.

${ }^{3}$ The following abbreviations will be used throughout this paper: The nucleoside triphosphates of adenine, uridine, cytosine, inosine, and guanosine will be represented by ATP, UTP, CTP, ITP, and GTP, respectively; the corresponding diphosphates by ADP, UDP, CDP, IDP, and GDP; 2,4-dinitrophenol by DNP; tris (hydroxymethyl)aminomethane buffer by Tris; tripolyphosphoric acid by PPP; the disodium salt of ethylenediaminetetraacetic acid by EDTA; $p$-chloromercuribenzoate by PCMB; and phenylmercuric acetate by PMA. 


\section{Materials and Methods}

Myosin B was prepared from rabbit muscle extracted in the cold for $5 \mathrm{hr}$. in WeberEdsall solution. The extract was filtered through glass wool, precipitated three times by the addition of $10 \mathrm{vol}$. water, and clarified by high-speed centrifugation, as previously reported (7). Protein concentration was measured by Kjeldahl, and phosphate concentration by Fiske-SubbaRow technique.

Nucleotides were purchased from Pabst (ATP, UTP, CTP, ADP) and from Sigma (ATP, ITP, GTP) and were used without further purification. Concentrations were checked by ultraviolet absorption measurements at appropriate wavelengths, using known absorption coefficients (8). DNP was purchsed from the Matheson Co. and recrystallized by dissolving in hot water, filtering while hot, and cooling. PPP, obtained from Fisher Scientific Co., was freed from orthophosphate and pyrophosphate by eluting from a Dowex 1 column with $\mathrm{KCl}$, following (with modifications) the general procedure of Peters and Riemann (9).

Rabbit psoas fibers were glycerinated according to the method of Szent-Györgyi (10). For experiments in which shortening was studied as a function of ATP concentration, the methods were similar to those already described (11), and $\bar{K}_{L}$, the reciprocal Michaelis-Menten constant as measured from length changes, was computed from the shortening data. Shortening was measured at room temperature, in $0.3 \mathrm{M}$ $\mathrm{KCl}, 10^{-3} \mathrm{M} \mathrm{Ca}^{++}$or $\mathrm{Mg}^{++}$, and at $\mathrm{pH} 7.0$ using barbital or Tris buffer. For experiments in which ATPase activity was measured, a large bundle of fibers was washed free of glycerol by immersion in ice-cold water and then put into a precooled Waring blendor for 30 sec. of blending. The blendor, with the partially homogenized musele, was then put into the freezing compartment of a refrigerator for $1 \mathrm{~min}$., after which another $30 \mathrm{sec}$. of blending was done. The process was repeated until a total of 2.5 min. of blending had been completed.

The rates of hydrolysis of the nucleotides by myosin $\mathrm{B}$ were measured at $25.5^{\circ} \mathrm{C}$., in $0.05 M$ Tris buffer at $\mathrm{pH} 7.0$, with $10^{-3} \mathrm{M} \mathrm{Ca}^{++}$, and at $\mathrm{KCl}$ concentrations specified below. The reagents were incubated in the water bath for $5 \mathrm{~min}$., and the timing clock was started when they were mixed. Samples were withdrawn every $20-30$ sec. thereafter, and were pipetted into $10 \%$ trichloroacetic acid. With few exceptions, five such points were obtained for each run. The velocity was computed from the slope of the best straight line through the points. For experiments in which $\bar{K}$, the reciprocal Michaelis-Menten constant, and $V$, the maximal velocity of the enzyme for the given conditions, were to be measured, five or six concentrations of substrate were used. The rate of ATP hydrolysis by homogenized fibrils was measured in an almost identical manner except that the suspension was stirred while the samples were being withdrawn.

The non-enzymic rates of hydrolysis were measured by immersing test tubes containing $6 \mathrm{ml}$. of the desired solution into a beaker of vigorously boiling water. The test tubes were loosely covered with glass stoppers to minimize evaporation. Onemilliliter samples were withdrawn at appropriate intervals and were blown from the pipette into $2 \mathrm{ml}$. of ice-cold distilled water, thus effectively terminating the hydrolysis. Phosphate was measured as described above.

\section{Results}

Data were obtained from several preparations of myosin B and of myofibrils. Values of $\bar{K}$ and of $V$ for these preparations and for the various nucleotides, in the presence and absence of DNP, were obtained from a 


\section{TABLE I}

Maximum Velocities of Hydrolysis, $V$ (moles/sec./g.), Reciprocal Michaelis-Menten Constants, $\bar{K}$ (l./mole), and the Product $\bar{K} V$ for Several Enzyme Preparations Acting upon Various Nucleotides in the Presence and Absence of DNP

$\mathrm{KCl}$ concentrations in moles/l. F stands for homogenized psoas myofibrils, and $\mathbf{M}$ for myosin B. The number after $\mathbf{F}$ or $\mathrm{S}$ identifies the particular preparation. All solutions were at $\mathrm{pH} 7.0$ and had $10^{-3} M \mathrm{Ca}^{++}$. The quantity $(V+/ V-)$ is the ratio of $V$ with DNP to $V$ without DNP, and similarly for $(\bar{K} V+/ \bar{K} V-)$ and $(\bar{K}-/ \bar{K}+)$.

\begin{tabular}{|c|c|c|c|c|c|c|c|c|c|c|c|}
\hline \multirow{2}{*}{ Enzyme } & \multirow{2}{*}[\mathrm{KCl}]{} & \multirow{2}{*}{$\mathrm{s}$} & \multicolumn{3}{|c|}{ No DNP } & \multicolumn{3}{|c|}{$10^{-3} M \mathrm{DNP}$} & \multirow{2}{*}{$\begin{array}{l}\bar{K}= \\
\bar{K}+\end{array}$} & \multirow{2}{*}{$\frac{V t}{V-}$} & \multirow{2}{*}{$\frac{\widetilde{K} V+}{\bar{K} V-}$} \\
\hline & & & $\underset{10^{-8}}{\vec{K} \times}$ & $V \times 10^{8}$ & $\bar{K} \underset{10^{3}}{V} \times$ & $\begin{array}{l}\bar{K} \times \\
10^{-3}\end{array}$ & $V \times 10^{6}$ & $\bar{K} V_{10^{2}} \times$ & & & \\
\hline F 3 & 0.3 & ATP & 6.38 & 1.96 & 12.5 & 5.60 & 2.35 & 13.2 & 1.14 & 1.20 & 1.05 \\
\hline F 4 & 0.3 & ATP & 8.08 & 1.59 & 12.8 & 7.20 & 2.22 & 16.0 & 1.12 & 1.39 & 1.24 \\
\hline F 5 & 0.3 & ATP & 20.7 & 2.22 & 46.0 & 16.4 & 2.91 & 47.8 & 1.26 & 1.31 & 1.04 \\
\hline M 4 & 0.3 & ATP & 27.7 & 5.41 & 150.0 & 16.7 & 8.70 & 145.0 & 1.66 & 1.61 & 0.97 \\
\hline M 4 & 0.3 & ITP & 3.54 & 16.9 & 59.8 & 3.74 & 16.3 & 61.0 & 一 & - & - \\
\hline M 4 & 0.3 & UTP & 8.01 & 8.55 & 68.5 & 7.51 & 10.5 & 78.9 & 1.07 & 1.23 & 1.15 \\
\hline M 5 & 0.3 & ATP & 38.5 & 12.7 & 489.0 & 33.3 & 16.7 & 556.0 & 1.16 & 1.31 & 1.13 \\
\hline M 5 & 0.3 & GTP & 3.35 & 26.3 & 88.0 & 4.30 & 21.3 & 92.0 & $\ldots$ & - & - \\
\hline M 5 & 0.3 & CTP & 15.6 & 5.2 & 81.1 & 14.4 & 7.1 & 102.0 & 1.08 & 1.37 & 1.27 \\
\hline M 1 & 0.3 & ATP & 33.5 & 6.33 & 212.0 & 33.3 & 8.00 & 266.0 & 1.01 & 1.26 & 1.25 \\
\hline M 4 & 0.3 & ATP & 20.7 & 2.22 & 46.0 & 16.4 & 2.91 & 47.7 & 1.26 & 1.31 & 1.04 \\
\hline M 10 & 0.3 & ATP & 28.7 & 4.44 & 127.4 & 21.4 & 6.37 & 136.3 & 1.34 & 1.43 & 1.07 \\
\hline M 10 & 0.3 & UTP & 6.43 & 5.71 & 36.7 & 4.33 & 9.09 & 39.4 & 1.49 & 1.59 & 1.07 \\
\hline M 11 & 0.3 & CTP & 9.36 & 2.15 & 20.1 & 8.79 & 2.94 & 25.8 & 1.07 & 1.36 & 1.27 \\
\hline \multicolumn{9}{|c|}{ Average } & 1.22 & 1.36 & 1.13 \\
\hline
\end{tabular}

Lineweaver-Burk graph of the data, and are listed in Table I. Most of the experiments were done with ATP as substrate. It was soon noted that at $0.3 M \mathrm{KCl}, 10^{-3} M \mathrm{DNP}$ seemed to raise $V$ and lower $\tilde{K}$ in such a way that the product $\bar{K} V$ was nearly unchanged (Fig. 1). This was observed for myofibrils and for myosin $B$, which emphasizes the enzymic similarity of these two systems despite their different levels of structural organization. The effect of DNP upon UTP and CTP is also to raise $V$ and lower $\bar{K}$ in such a way that $\bar{K} V$ remains roughly constant. Actually, the ratio of $\bar{K} V$ in the presence of DNP $(\vec{K} V+)$ to $\vec{K} V$ in the absence of $\mathrm{DNP}(\widetilde{K} V-)$ is not randomly distributed about 1 , but averages 1.13 . This difference is significant to within the $1 \%$ level when judged by a $t$-test, and shows that the product $\bar{K} V$ does change when DPN is added. As can be seen from Table I, this comes about because DNP causes $V$ to increase somewhat more than it causes $\bar{K}$ to decrease. Although the ratio $(\bar{K} V+) /(\bar{K} V-)$ is not unity, it is evident that DNP causes $\bar{K}$ and $V$ to change in opposite directions and by almost compensating amounts for the substrates ATP, 


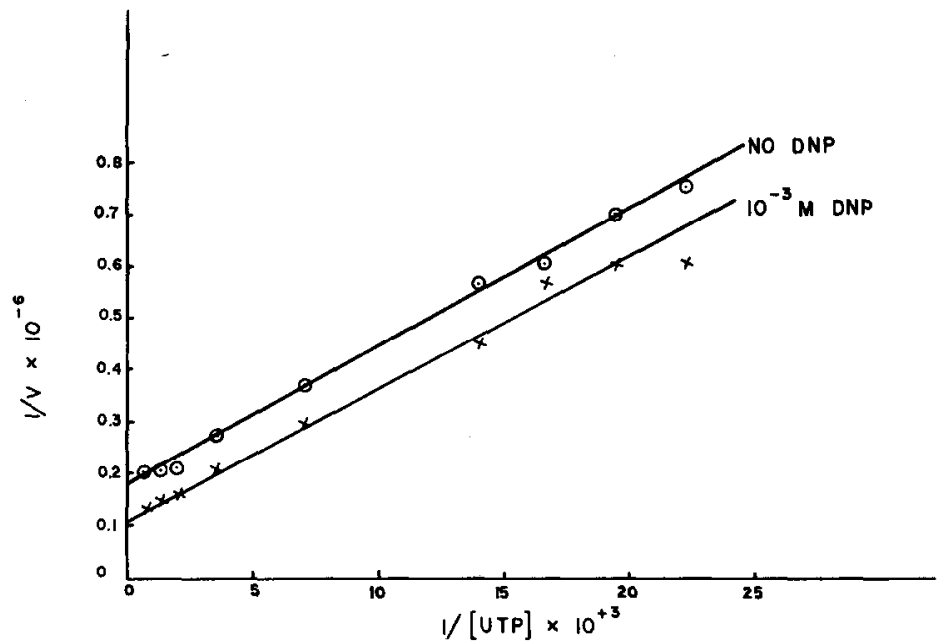

FIG. 1. Lineweaver-Burk graph for myosin No. 10, with UTP as substrate, at $25.7^{\circ} \mathrm{C}$., in $0.3 \mathrm{M} \mathrm{KCl}, 10^{-3} M \mathrm{Ca}^{++}, 0.05 M$ Tris, pH 7.0.

CTP, and UTP. For GTP and ITP the effects of DNP are quite small, and possibly in the opposite direction to the effects on the other nucleotides.

It was previously shown (6) that ADP is a better inhibitor of ITPase activity than it is of ATPase activity, an observation which was interpreted in accordance with the idea that the adenine ring is bound more tightly to the site than the inosine ring. Since DNP has very little effect on ITPase activity at $0.3 M \mathrm{KCl}$ (Tables I and II), it was of interest to ascertain whether DNP would affect the inhibition of ITPase activity

TABLE II

Effect of $A D P$ and DNP on ITPase Activity of Myosin $B$ in $10^{-3} \mathrm{MCa}^{++}, 0.3 \mathrm{M} \mathrm{KCl}, 0.05 \mathrm{M}$ Tris $\mathrm{pH} \gamma$

\begin{tabular}{ccccc}
\hline$\left[\begin{array}{l}{\left[0^{-4}\right]} \\
10^{-}\end{array}\right.$ & $\begin{array}{c}{[\mathrm{ADP}]} \\
10^{-8} M\end{array}$ & $\begin{array}{c}{[\mathrm{DNP}]} \\
\left.10^{-8} \mathrm{M}\right]\end{array}$ & Micromoles split/sec./s. & $\%$ \\
\hline 3.0 & - & - & 6.89 & 100.0 \\
3.0 & - & 1.0 & 7.05 & 102.0 \\
3.0 & 1.0 & - & 1.74 & 25.3 \\
3.0 & 1.0 & 1.0 & 2.14 & 31.0 \\
2.0 & - & - & 4.65 & 100.0 \\
2.0 & - & 1.0 & 4.95 & 107.0 \\
2.0 & 0.33 & - & 2.51 & 54.2 \\
2.0 & 0.33 & 1.0 & 3.09 & 66.7 \\
2.0 & 0.11 & - & 3.40 & 73.3 \\
2.0 & 0.11 & 1.0 & 4.10 & 88.4 \\
\hline
\end{tabular}


TABLE III

Tripolyphosphatase Activity of Myosin $B$ at $0.3 \mathrm{M} \mathrm{KCl}, 0.05 \mathrm{M}$ Tris, $\mathrm{pH} 7.0,10^{-3} \mathrm{M} \mathrm{Ca}^{++}, 25.5^{\circ} \mathrm{C}$.

\begin{tabular}{ccc}
\hline $\begin{array}{c}{[\mathrm{TPP}]} \\
M M^{3} \times 10^{3}\end{array}$ & {$[\mathrm{DNP}]$} & $\begin{array}{c}\text { Rate } \\
\text { moles } / \text { sec. } / g .\end{array}$ \\
\hline 1.53 & 0 & 0.50 \\
1.53 & $10^{-3}$ & 0.28 \\
0.75 & 0 & 0.33 \\
0.75 & $10^{-3}$ & 0.15 \\
\hline
\end{tabular}

caused by ADP. The data presented in Table II show that DNP decreased the inhibitory action of ADP on ITPase activity, thus suggesting that DNP may interfere with the binding of the $\mathrm{NH}_{2}$ group of the adenine ring.

Since PPP does not have a purine or pyrimidine ring, one might expect that DNP would have little effect on its rate of hydrolysis. The results (Table III), however, showed a considerable inhibitory effect, which, since it also occurred at PPP concentrations below the concentration of $\mathrm{Ca}^{++}$ in the system, was probably not due to the removal of $\mathrm{Ca}^{++}$by chelation with PPP.

The data from measurements of steady-state lengths of psoas fibers at different concentrations of ATP were plotted in the manner discussed by Blum, Kerwin, and Bowen (11), and the resulting $\bar{K}_{L}$ values are presented in Table IV. It is evident that $10^{-3} M$ DNP decreased $\bar{K}_{L}$, i.e., decreased the effectiveness of ATP as a shortening agent for the fibrils, and that $\mathrm{Mg}^{++}$ could still increase $\bar{K}_{L}$ in the presence of DNP. Similar measurements, but at only two concentrations of substrate, are presented in Table $V$ for the five nucleotides employed in this study. The most effective nucleotides are ATP, CTP > UTP > ITP, GTP. The ability of DNP to decrease the shortening caused by the nucleotides was most marked at concentrations of nucleotides and of bivalent cation that caused considerable shortening.

TABLE IV

Values of $\bar{K}_{L} \times 10^{-3}($ l./mole) for Psoas Fibers between 150 and $800 \mu$ in Diameter, in $0.3 \mathrm{M} \mathrm{KCl}, 0.025 \mathrm{M}$ Barbital Buffer, $\mathrm{pH} 7.0$, at Room Temperature

\begin{tabular}{|c|c|c|c|}
\hline $\begin{array}{l}{[\mathrm{DNP}]} \\
{\left[\mathrm{Mg}^{++}\right]}\end{array}$ & $\begin{array}{l}10^{-3} M \\
10^{-8} M\end{array}$ & $\stackrel{10^{-2}: M}{0}$ & $\begin{array}{l}0 \\
\mathbf{0}\end{array}$ \\
\hline & 15.7 & 10.0 & 30.0 \\
\hline & 22.7 & 8.8 & 12.0 \\
\hline & 16.7 & 6.7 & \\
\hline & & 6.5 & \\
\hline & & 5.6 & $14.0-36.0^{a}$ \\
\hline & & 15.0 & \\
\hline
\end{tabular}

a These values were obtained by Blum, Kerwin, and Bowen (11). 


\section{TABLE V}

Effect of $10^{-3} M$ DNP on the Shortening of Psous Fibers Caused by Various Nucleotides at $0.3 \mathrm{M} \mathrm{KCl}, \mathrm{pH} 7.0$, Room Temperature

The fibers were approximately $150 \mu$ in diameter and were used in groups of three. The combined length in distilled water $(90-120 \mathrm{~mm}$.) was normalized to $100 \mathrm{~mm}$. After the fibers reached their steady-state length in the presence of $10^{-3} \mathrm{M} \mathrm{Ca}{ }^{++}$, $5 \times 10^{-3} M \mathrm{Mg}^{++}$was added directly to the solutions (using a small volume of a concentrated $\mathrm{MgCl}_{2}$ solution), and the new steady-state lengths of the fibers were then measured. The nucleotide concentrations were $4.0 \times 10^{-3} \mathrm{M}$ and $1.0 \times 10^{-3} \mathrm{M}$. The concentration of $\mathrm{Ca}^{++}$is $10^{-3} \mathrm{M}$ and of $\mathrm{Mg}^{++}$is $5.0 \times 10^{-3} \mathrm{M}$.

\begin{tabular}{|c|c|c|c|c|c|}
\hline & & \multicolumn{2}{|c|}{$4.0 \times 10^{-3} \mathrm{M}$} & \multicolumn{2}{|c|}{$1.0 \times 10^{-3} \mathrm{M}$} \\
\hline & & No DNP & $10^{-3} M \mathrm{DNP}$ & No DNP & $10^{-3} M \mathrm{DNP}$ \\
\hline \multirow{2}{*}{ ATP } & $\mathrm{Ca}^{++}$ & 23 & 32 & 39 & 44 \\
\hline & $+\mathrm{Mg}^{++}$ & 17 & 21 & 27 & 30 \\
\hline \multirow[t]{2}{*}{ CTP } & $\mathrm{Ca}^{++}$ & 20 & 27 & - & - \\
\hline & $+\mathrm{Mg}^{++}$ & 20 & 22 & - & - \\
\hline \multirow{2}{*}{ U'TP } & $\mathrm{Ca}^{++}$ & 28 & 32 & 91 & 89 \\
\hline & $+\mathrm{Mg}^{++}$ & 19 & 25 & 38 & 43 \\
\hline \multirow[t]{2}{*}{ ITP } & $\mathrm{Ca}^{++}$ & 82 & 80 & 88 & 83 \\
\hline & $+\mathbf{M g}^{++}$ & 33 & 52 & 37 & 54 \\
\hline \multirow{2}{*}{ GTPa } & $\mathrm{Ca}^{++}$ & 85 & 93 & 99 & 98 \\
\hline & $+\mathrm{Mg}^{++}$ & - & - & 45 & 45 \\
\hline
\end{tabular}

a For GTP the $\mathrm{Mg}^{++}$concentration was $10^{-3} \mathrm{M}$ instead of $5 \times 10^{-3} \mathrm{M}$.

The effect of DNP on the hydrolysis of ATP and of ITP by myofibrils was investigated in the absence of added bivalent cation and in the presence of $\mathrm{Ca}^{++}$and $\mathrm{Mg}^{++}$(Table VI). In the presence of $\mathrm{Ca}^{++}$, DNP increased ATPase activity and had little effect on ITPase activity (as was found for myosin B), whereas DNP accelerated both the ATPase and the ITPase activity of the fibrils in the presence of $\mathrm{Mg}^{++}$. In the absence of added bivalent cation, DNP had a small and variable effect on the ATPase activity of myofibrils.

\section{TABLE VI}

Effect of DNP on ATPase and ITPase Activities of Psoas Fibrils at $0.3 \mathrm{M} \mathrm{KCl,0.025}$ $M$ Barbital Buffer at $p H$ 7.0, Room Temperature

$\left[\mathrm{Mg}^{++}\right]$or $\left[\mathrm{Ca}^{++}\right]$is $1.28 \times 10^{-3} \mathrm{M}$, [ATP] is $7.42 \times 10^{-4} M$, and [ITP] is $8.33 \times$ $10^{-4} M$.

\begin{tabular}{|c|c|c|c|}
\hline Cation & [DNP] & ATPase & ITPase \\
\hline & $M$ & \multicolumn{2}{|c|}{ $\mu$ moles/sec./g. } \\
\hline $\mathrm{Mg}^{++}$ & 0 & 0.88 & 1.62 \\
\hline $\mathrm{Mg}^{++}$ & $10^{-3}$ & 1.24 & 1.91 \\
\hline $\mathrm{Ca}^{++}$ & 0 & 2.43 & 3.92 \\
\hline $\mathrm{Ca}^{++}$ & $10^{-3}$ & 3.02 & 3.82 \\
\hline
\end{tabular}


TABLE VII

Effect of DNP on the EDTA-Activated ATPase Activity of Myosin B

Concentrations are in moles $/ 1$. The ATPase rate is in $\mu$ moles $/ \mathrm{sec} . / \mathrm{g}$. Conditions are : $0.3 \mathrm{M} \mathrm{KCl,} 0.05 M$ Tris, $\mathrm{pH} 7.0,25.5^{\circ} \mathrm{C}$.

\begin{tabular}{ccc}
\hline$[\mathrm{FDTA}]$ & {$[\mathrm{DNP}]$} & Rate \\
\hline 0 & 0 & 1.55 \\
$3.0 \times 10^{-4}$ & 0 & 7.50 \\
$3.0 \times 10^{-4}$ & $1.0 \times 10^{-4}$ & $6.02)$ \\
$3.0 \times 10^{-4}$ & $3.0 \times 10^{-4}$ & 6.31 \\
$3.0 \times 10^{-4}$ & $1.0 \times 10^{-3}$ & 5.05 \\
0 & 0 & 0.95 \\
$1.0 \times 10^{-3}$ & 0 & 9.59 \\
$1.0 \times 10^{-3}$ & $1.0 \times 10^{-4}$ & 9.79 \\
$1.0 \times 10^{-3}$ & $3.0 \times 10^{-4}$ & 8.17 \\
$1.0 \times 10^{-3}$ & $1.0 \times 10^{-3}$ & 7.44 \\
$2.0 \times 10^{-3}$ & 0 & \\
$2.0 \times 10^{-3}$ & $1.0 \times 10^{-3}$ & 4.31 \\
\hline
\end{tabular}

There are several similarities between the actions of DNP and of EDTA. Both decrease the shortening of fibers caused by ATP, both accelerate ATPase activity and, under certain conditions, inhibit ITPase activity. Since it has already been suggested (6) that EDTA might act by decreasing the binding of the position six substituent on the ring to the enzymic site, it was of interest to ascertain whether the activator DNP would compete with the activator EDTA. It was found (Table VII and Fig. 2) that the marked acceleration caused by EDTA can be partially decreased by DNP. The data suggest that EDTA is bound more strongly to the myosin (in the presence of ATP) than is DNP (which, presumably, is also bound to myosin only in the presence of ATP).

Nanninga (12) has recently suggested that several of the effects of $\mathrm{Ca}^{++}$ and $\mathrm{Mg}^{++}$on the myosin-catalyzed hydrolysis of ATP may be related to the differences in stability between the $\mathrm{Ca}^{++}$and $\mathrm{Mg}^{++}$complexes of ATP. The question naturally arose as to whether the effects of DNP, $\mathrm{Ca}^{++}$, and $\mathrm{Mg}^{++}$on the hydrolysis of the nucleoside triphosphates (NTP) studied in these experiments would parallel the enzymic behavior, in which case it might be erroneous to ascribe the observed differences in $\bar{K}$ and $V$ to differences in degree of ring interaction with the enzymic site. The hydrolysis of the NTP at $100^{\circ} \mathrm{C}$. was therefore measured at several salt concentrations and in the presence and absence of $\mathrm{Ca}^{++}, \mathrm{Mg}^{++}$, and DNP. Since the concentration of $\mathrm{Ca}^{++}$or $\mathrm{Mg}^{++}$, when present, was five times the NTP 


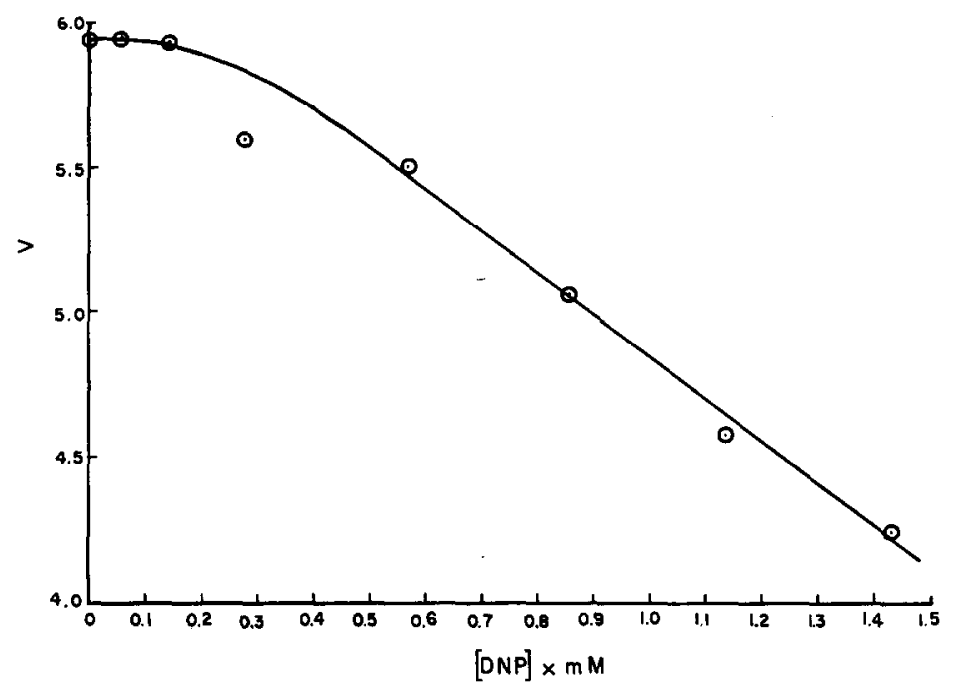

FIG. 2. Effect of DNP on EDTA-activated myosin in $0.3 \mathrm{M} \mathrm{KCl}, 0.05 \boldsymbol{M}$ Tris, $\mathrm{pH}$ 7.0 , at $25.7^{\circ} \mathrm{C}$. [EDTA] $=2.0 \times 10^{-3} M$; $\left[\right.$ Myosin] $=0.0482 \mathrm{~g} . / \mathrm{l}$; [ATP] $=10^{-3} \mathrm{M}$. The units of the activity, $V$, are micromoles of phosphate split/sec./g. myosin. The activity without EDTA and without DNP was $2.53 \mu$ moles $/ \mathrm{sec} . / \mathrm{g}$.

concentration, most of the NTP was present as the complex 4 [cf. Table I of Nanninga (12)]. Bccause of the fairly high rate of hydrolysis in the presence of $\mathrm{Ca}^{++}$, the rate of hydrolysis decreased at times greater than about 1000 sec. in a few experiments. In such experiments the initial slope was used to compule $k_{1}$, the apparent first-order rate constant for the splitting of the N'TP. Since the kinetic formulation has been presented by Nanninga (12), it will not be repeated here. It can be seen from the results shown in Table VIII that the non-enzymic alkaline hydrolysis rates of the NTP, are, to a first approximation, independent of the ring structure of the NTP. The addition of $\mathrm{Ca}^{++}$approximately doubles the rate of hydrolysis under our conditions, in agreement with Nanninga's observation (12). The addition of $\mathrm{Mg}^{++}$caused a small increase in hydrolysis rate at high $\mathrm{KCl}$ or $\mathrm{NaCl}$, and a considerable increase in rate at lower salt concentrations, in agreement with Spicer (13) but contrary to the results of Nanninga (12). The rate of hydrolysis of ATP is rather insensitive to salt concentration in the absence of added bivalent cation, but decreases about $20 \%$ as the $\mathrm{NaCl}$ concentration is increased from 0.025 to $0.10 \mathrm{M}$. There is

${ }^{4}$ Although $10^{-3} \mathrm{M}$ GTP is soluble at $\mathrm{pH} 8.5$ in the presence of $10^{-3} \mathrm{M} \mathrm{Ca}^{++}$, an insoluble complex is formed even at $\mathrm{pH} 7.5$ in the presence of $5.0 \times 10^{-3} \mathrm{M} \mathrm{Ca}^{++}$(and, to a lesser extent, $5.0 \times 10^{-3} \mathrm{M} \mathrm{Mg}^{++}$). At $100^{\circ} \mathrm{C}$., however, enough was in solution or in very fine suspension so that the observed hydrolysis rate for GTP was the same as for the other NTP. 
TABLE VIII

Hydrolysis of Nucleoside Triphosphates at $100^{\circ} \mathrm{C} ., 0.05 \mathrm{M}$ Tris Buffer of $p H 8.50$

$10^{-3} M \mathrm{NTP}, 5.0 \times 10^{-3} M \mathrm{Ca}^{++}$or $\mathrm{Mg}^{++}$, and salt concentration as indicated. The sodium from the ATP is not included in the salt concentrations shown.

\begin{tabular}{|c|c|c|c|c|}
\hline \multirow{2}{*}{ NTP } & \multirow{2}{*}{ Salt } & \multicolumn{3}{|c|}{$k_{1} \times 10^{8} \min ^{-1}$} \\
\hline & & Control & $+\mathrm{Ca}^{++}$ & $+\mathrm{Mg}^{++}$ \\
\hline ATP & $\mathrm{KCl}, 0.3 \mathrm{M}$ & 9.9 & 22.0 & 10.5 \\
\hline ITP & $\mathrm{KCl}, 0.3 M$ & 10.0 & 19.2 & 11.3 \\
\hline UTP & $\mathrm{KCl}, 0.3 M$ & 9.0 & 19.0 & 10.9 \\
\hline GTP & $\mathrm{KCl}, 0.3 \mathrm{M}$ & 10.4 & 20.4 & 11.1 \\
\hline CTP & $\mathrm{KCl}, 0.3 M$ & 9.1 & 17.8 & 9.6 \\
\hline ATP & $\mathrm{KCl}, 0$ & - & - & 15.0 \\
\hline ATP & $\mathrm{KCl}, 0.025 M$ & - & - & 14.4 \\
\hline ATP & $\mathrm{KCl}, 0.20 \mathrm{M}$ & - & - & 10.7 \\
\hline$\Lambda \mathrm{TP}$ & $\mathrm{NaCl}, 0.025 M$ & 9.8 & - & 14.5 \\
\hline $\mathrm{ATP}$ & $\mathrm{NaCl}, 0.10 \mathrm{M}$ & 9.5 & - & 11.7 \\
\hline ATP & $\mathrm{NaCl}, 0.40 M$ & 9.2 & - & 10.8 \\
\hline
\end{tabular}

no noticeable difference between the effects of $\mathrm{Na}^{+}$and of $\mathrm{K}^{+}$ions on the non-enzymic hydrolysis. As can be seen from Fig. 3, DNP had no effect on the $100^{\circ} \mathrm{C}$. hydrolysis rate of ATP in $0.3 \mathrm{M} \mathrm{KCl}$ alone or with the addition of $\mathrm{Ca}^{++}$or $\mathrm{Mg}^{++}$.

\section{Discussion}

It has been shown (6) from light scattering and from enzymic rate of hydrolysis studies on myosin $\mathrm{B}$ in $0.6 \mathrm{M} \mathrm{KCl}, \mathrm{pH} 7.0,10^{-3} M \mathrm{Ca}^{++}$, that $\bar{K}(\mathrm{ATP})>\bar{K}(\mathrm{UTP})>\bar{K}(\mathrm{ITP})$, while $V(\mathrm{ATP})<V$ (UTP) $<V$ (ITP). The magnitudes of $\bar{K}$ as determined by light scattering increased considerably if $\mathrm{Mg}^{++}$was substituted for $\mathrm{Ca}++$, but the sequence of $\bar{K}$ remained unchanged. The sequence of $V$ was also unchanged when $\mathrm{Ca}^{++}$was replaced by $\mathrm{Mg}^{++}$, although $V$ (ATP) was considerably inhibited and $V$ (ITP) was somewhat accelerated. These and other observations led to the idea that the rate of desorption of the nucleoside diphosphate formed after hydrolysis of the terminal $\mathrm{P}-\mathrm{O}-\mathrm{P}$ bond played a role in the observed net enzymic rate, and the following scheme (Fig. 4) was used to analyze the data.

In the steady state,

$$
v=h E_{0} /\left\{1+\left(h / j_{2}\right)+\left(1+\left[\mathrm{P}_{2}\right] J_{-2}\right) / \bar{K}_{0}[\mathrm{~S}]\right\},
$$

where $J_{-2}=j_{-2} / j_{2}, \bar{K}_{0}=k_{1} /\left(k_{-1}+h\right)$, and $\mathrm{P}_{2}$ represents the nucleoside 


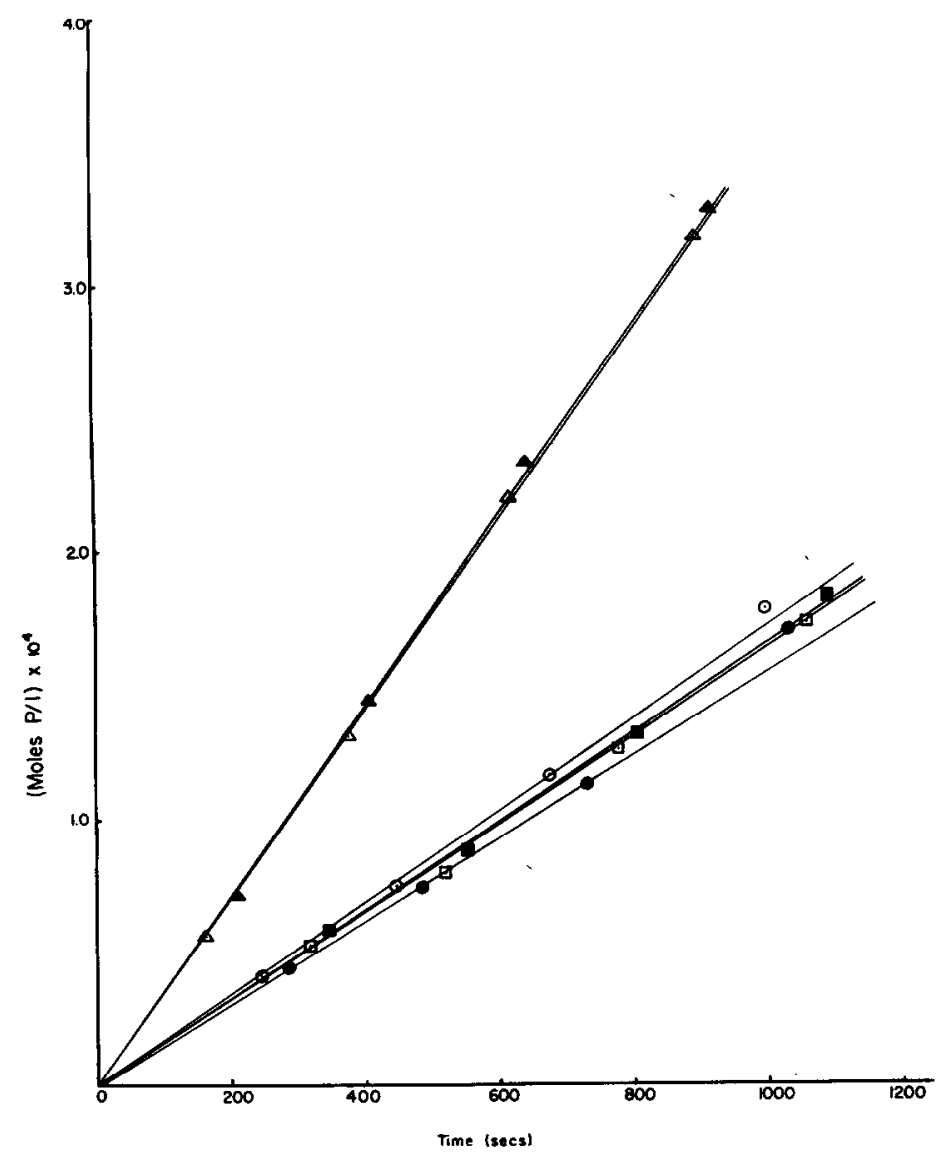

FIg. 3. Effect of DNP on the non-enzyme hydrolysis of ATP. Conditions are: 0.3 $M \mathrm{KCl}, 0.05 M$ Tris, $\mathrm{pH} 8.50,10^{-3} \mathrm{M}$ ATP, $100^{\circ} \mathrm{C}$. The meanings of the symbols and the values of the rate constant, $k_{1} \times 10^{+3} \mathrm{~min}^{-1}$, are as follows: $O$, no DNP, $k_{1}=$ $10.8 ; 0,10^{-3} M$ DNP, $k_{1}=9.5 ; \triangle, 5.0 \times 10^{-3} M \mathrm{Ca}^{++}, k_{1}=22.0 ; \Delta, 5.0 \times 10^{-3} \mathrm{M}$ $\mathrm{Ca}^{++}$and $10^{-3} \mathrm{M} \mathrm{DNP}, k_{1}=22.2 ; \square, 5.0 \times 10^{-3} \mathrm{M} \mathrm{Mg} \mathrm{Mg}^{++}, k_{1}=10.0 ; \square, 5.0 \times 10^{-3} \mathrm{M}$ $\mathrm{Mg}^{++}$and $10^{-3} M$ DNP, $k_{1}=10.2$.

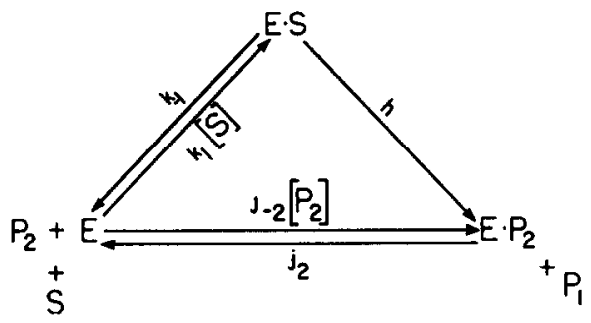

FIg. 4. Kinetic reaction scheme for an enzyme in which one of the reaction products is not desorbed instantaneously from the active site. 
diphosphate. It can be seen that $V^{\text {app }}=h E_{0} /\left\{1+\left(h / j_{2}\right)\right\}$ and $\bar{K}^{\text {app }}=$ $\bar{K}_{0}\left\{1+\left(h / j_{2}\right)\right\}\left\{1+\left[\mathrm{P}_{2}\right] J_{-2}\right\}$. For small $\left[\mathrm{P}_{2}\right], \bar{K}^{\text {app }} \sim \bar{K}_{0}\left\{1+\left(h / j_{2}\right)\right\}$. From the data on the sequence of $\bar{K}^{\text {upp }}$ and of $V^{\text {upp }}$ it was assumed (6) that $j_{2}$ would be smallest for ADP and CDP, intermediate for UDP, and largest for IDP and GDP. It was also suggested that $\mathrm{Mg}^{++}$slightly increased and $\mathrm{Ca}^{++}$considerably increased the $\mathrm{P}-\mathrm{O}-\mathrm{P}$ bond lysis step (rate constant $h$, Fig. 4). The results shown in Table VIII support the view that the $\mathrm{P}-\mathrm{O}-\mathrm{P}$ bond lysis step catalyzed by myosin is similar to the non-enzymic hydrolysis. In addition to the similar effects that $\mathrm{Ca}^{++}$and $\mathrm{Mg}^{++}$have on both types of hydrolysis, the rate increases linearly with $\mathrm{OH}^{-}$concentration (14) and increases with decreasing $\mathrm{KCl}$ concentration in the presence of $\mathrm{Ca}^{++}(15)$. Friess (16) noted also that the acid-catalyzed rate of ATP hydrolysis was of the same order of magnitude as the myosin-catalyzed rate. It therefore seems that the differences observed between the various nucleoside triphosphates are indeed due to differences in the binding of the NTP ring to the enzymic site, and that many of the effects of $\mathrm{Mg}^{++}$are due to its interaction with the protein [cf., however, Nanninga (12)].

Since DNP has no effect on the non-enzymic rate of hydrolysis of ATP (Fig. 3), and since under the conditions of these experiments DNP accelerates the myosin-catalyzed hydrolysis of ATP, UTP, and CTP but not of ITP or GTP, it seems reasonable to suggest that DNP acts by changing the interaction of the purine or the pyrimidine ring with the enzymic site. If a substance such as DNP acted primarily by increasing $j_{2}$, then one would expect that $\bar{K}^{\text {app }}$ and $V^{\text {app }}$ would change in such a way that their product would remain constant, since $\bar{K}^{\text {app }} V^{\text {app }}=h E_{0} \bar{K}_{0} .{ }^{5}$ The data in Table I show that in $0.3 \mathrm{M} \mathrm{KCl}$ this condition is nearly (but not exactly) fulfilled. This effect should be largest for ATP and CTP, which are bound most tightly to the site, and smallest for ITP and GTP, which are bound least tightly to the site. By reducing the binding of the adenine ring, the DNP would decrease the effectiveness of ADP as an inhibitor of ITPase action (Table II).

We have already commented upon certain similarities between the actions of EDTA and of DNP. EDTA is considerably more potent in its effects, however, since it causes a large acceleration of ATPase (17) and an appreciable inhibition of ITPase activity (18). If the DNP in any way competed with EDTA for the site, one would expect that DNP, although an activator itself, should decrease the activation by EDTA of myosin B (Table VII and Fig. 2). The applicability of the scheme shown in Fig. 4 to the interpretation of some of the effects of EDTA on myosin is further supported by the recent evidence of Tonomura et al. (19), who showed that

${ }^{5}$ In what follows we shall use $\bar{K}$ and $V$ to mean the apparent (i.e., experimentally measured) values of the parameters. 
over a wide range of EDTA concentrations, and hence over a considerable range of $\bar{K}$ and $V$, the product $\bar{K} V$ remained approximately constant. Thus it appears that EDTA is similar to DNP in its action on the desorption of the product. EDTA, however, presumably because of its chelating ability and its negative charge is not only more potent than DNP but also has a marked ability to act as a relaxing factor (20). Greville and Reich (21) have also noted a similarity between the action of DNP and EDTA on the nucleoside triphosphates, and also suggest that these activators may act by affecting the interaction between the purine and pyrimidine six position and the myosin. That the similarity is not due to any ability of DNP to act as a chelator is supported by their finding (21) that pentachlorophenol also accelerates ATPase activity. Nevertheless, one must not overstate the analogy between the effects of EDTA and DNP, since the data shown in Fig. 2 do not suggest a simple competition between EDTA and DNP. Furthermore, Tonomura and Kitagawa (22) have shown that the initial fast phase of ATPase activity by myosin is affected differently by EDTA and by DNP.

Gilmour and Griffiths (23), who also noted a similarity between the effects of DNP and EDTA on myosin, have discussed the action of DNP in terms of presumed changes in the physical state of the myosin rather than in kinetic terms.

If the strength of binding of the ring to the site is directly concerned with the intensity of contractile events, then DNP, by reversibly (3) reducing the strength of this binding (Table I), should decrease the shortening caused by a given concentration of NTP (Tables IV and V), even if the rate of hydrolysis is increased by DNP. ${ }^{6}$ The data in Table V show that the sequence of ability to cause shortening (in the presence of either $\mathrm{Ca}^{++}$or of $\mathrm{Ca}^{++}$and $\mathrm{Mg}^{++}$) is the same as the sequence of $\bar{K}$ found for myosin B, i.e., ATP and CTP better than UTP which in turn is considerably better than ITP and GTP. In $0.1 M \mathrm{KCl}$ Hasselbach (24) found that the sequence of effectiveness of the nucleotides in causing the development of tension in fibers was the same as the sequence of splitting, and so concluded that Blum's (6) view (i.e., a correlation between the mechanical events as seen in light scattering and the $\bar{K}$ ) was in error. The sequence of $\bar{K}$ for myosin $\mathrm{A}$ at $0.1 \mathrm{M} \mathrm{KCl}$, however, is the same as the sequence at high $\mathrm{KCl}$ [Kielley et al. (25)], and this may also be true for myosin $\mathrm{B}$. At $0.3 \mathrm{M} \mathrm{KCl}$ there is some correlation between the sequence of $\bar{K}$ and the steady-state shortening (Table V), but not between the rate of splitting

\footnotetext{
${ }^{6}$ The increase in rate of hydrolysis caused by DNP is fairly small even for ATP, and the mechanical effect cannot therefore be an artifact of diffusion. For ITP there is essentially no effect of DNP on splitting and yet a clear decrease in the shortening in the presence of $\mathrm{Mg}^{++}$.
} 
and the shortening. Furthermore, DNP decreases both the shortening and the $\bar{K}$ for ATP, CTP, and UTP, but increases the splitting rate of these substrates. Thus it seems that the strength of binding of the nucleotide to the myosin is of some importance in determining the contractile events, at least as they are measured by shortening at zero load.

Statistically, DNP causes $V$ to increase somewhat more than $\bar{K}$ decreases. Hence, the kinetic consequences of the scheme shown in Fig. 4 are not strictly obeyed. This may result from two causes: (a) We have not accounted for the contributions of the particular $\mathrm{KCl}, \mathrm{DNP}, \mathrm{Ca}^{++}$, and $\mathrm{H}^{+}$ ions at which these experiments have been performed. (b) It is possible that other kinetic schemes would equally well explain our data and the results of others. This is especially true in view of the homeomorphism between several conceptually different kinetic schemes used to describe the enzymic behavior of myosin, as has been pointed out by Morales et al. (26). Possibly another kinetic scheme would explain the inhibition of PPPase activity by DNP, an observation which cannot be explained by the intcrpretation so far used.

Perhaps the simplest alternative would be to assume that $k_{2} \gg k_{-1}$ in the usual Michaelis-Menten formulation

$$
\mathrm{E}+\mathrm{S} \underset{k_{-1}}{\stackrel{k_{1}}{\rightleftarrows}} \mathrm{E} \times \mathrm{S} \stackrel{k_{2}}{\longrightarrow} \mathrm{E}+\mathrm{P} .
$$

Then, if DNP caused $k_{2}$ to increase, one would necessarily find that $\bar{K} V$ remained constant, since $\bar{K} V=k_{1} E_{0}$ is independent of $k_{2}$. The experiments of Ouellet et al. (27), however, suggest that $\bar{K}$ observed for myosin B under similar conditions is an equilibrium constant, i.e., that $k_{2} \ll k_{-1}$. Furthermore, an assumption that DNP increased $k_{2}$ would not explain the lack of effect of DNP on ITPase and GTPase activity, nor would it explain the inhibition of PPPase activities.

Another scheme that might be considered is a generalized form of the Michaelis-Menten scheme, such as that of Botts and Morales (28). It can be shown that it is improbable for a modifier (such as DNP) to increase $V$ and decrease $\bar{K}$ in such a way that $\bar{K} V$ remains constant. Since the present data show that $\vec{K} V$ does not remain strictly constant, the scheme of Botts and Morales (28) or similar kinetic schemes cannot be ruled out. The formulation used in Fig. 4 is consistent with most of the data, however, and introduces a minimum of new kinetic parameters.

These results suggest that DNP acts on myosin by decreasing the binding of the purine or pyrimidine ring to the enzymic site, but offer no insight into the mechanism by which DNP affects the site. Several lines of evidence $(2,3,23,29,30)$ point to a significant role for - $\mathrm{SH}$ groups in the interaction of myosin with its substrates and with EDTA and DNP. In 
the yeast alcohol dehydrogenase system, where we suggested, in analogy with myosin, that the amine group on the adenine ring of diphosphopyridine nucleotide helped bind the coenzyme to the enzymic site (6), Van Eys et al. (31) have recently shown that $-\mathrm{SH}$ groups are involved in this process.

\section{Summary}

1. The effects of 2,4-dinitrophenol (DNP) on the interaction of several nucleoside triphosphates with myosin $\mathrm{B}$ and glycerol-treated psoas fibers

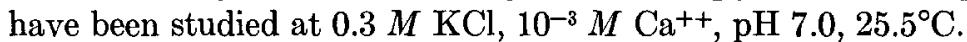

2. The sequence of reciprocal Michaelis-Menten constants, $\bar{K}$, is $\bar{K}$ (ATP $>\bar{K}(\mathrm{CTP})>\bar{K}($ UTP $)>\bar{K}($ GTP, ITP $)$. The sequence of maximal splitting velocities, $V$, is $V$ (ITP, GTP) $>V$ (UTP) $>V($ ATP $)>$ $V$ (CTP). These sequences are unchanged by DNP.

3. For ATP, CTP, and UTP, DNP raises $V$ and lowers $\vec{K}$ in a nearly compensatory way.

4. DNP reduces the inhibition of ITPase activity by ADP, decreases the activation of ATPase activity by EDTA, and inhibits the rate of splitting of tripolyphosphate.

5. The non-enzymic alkaline hydrolysis rates of ATP, UTP, GTP, CTP, and ITP are about equal at $\mathrm{pH} 8.5,0.3 \mathrm{M} \mathrm{KCl}, 100^{\circ} \mathrm{C}$. The addition of $\mathrm{Mg}^{++}$slightly increases the rate. $\mathrm{Ca}^{++}$approximately doubles the rate. DNP has no effect. Decreasing the salt concentration increases the rate.

6. DNP decreases the amount of shortening of unloaded psoas fibers.

7. The results have been discussed in terms of a kinetic scheme which assumes that the rate of desorption of the nucleoside diphosphate product of the reaction may be rate limiting under certain conditions.

\section{REFERENCES}

1. Webster, H. L., Ph.D. Dissertation, Cambridge University, 1953.

2. Greville, G. D., and Needham, D. M., Biochim. et Biophys. Acta 16, 284 (1955).

3. Cha ppell, J. B., And Perry, S. V., Biochim. et Biophys. Acta 16, 285 (1955).

4. Lardy, H. A., and Wellman, H., J. Biol. Chem. 201, 357 (1953).

5. Kielley, W. W., And Kielley, R. K., J. Biol. Chem. 191, 485 (1951).

6. Вцuм, J. J., Arch. Biochem. Biophys. 65, 486 (1955).

7. Botts, J., And Morales, M. F., J. Cellular Comp. Physiol. 37, 27 (1951).

8. Pabst Laboratories Circular OR-10, 1956.

9. Peters, T. V., and Riemann, W., Anal. Chim. Acta 14, 131 (1956).

10. Szent-Györgyi, A., Biol. Bull. 96,140 (1949).

11. Buvm, J. J., Kerwin, T. D., And Bowen, W. J., Arch. Biochem. Biophys. 66, 100 (1957).

12. Nanninga, L. B., J. Phys. Chem. 61, 1144 (1957).

13. Spicer, S. S., J. Biol. Chem. 199, 301 (1952).

14. Ouellet, L., and Morales, M. F., Congr. intern. biochim., $2^{*}$ Congr., Paris, Abstr. p. 237. 
15. Laidler, K. J., And Beardell, A. J., Arch. Biochem. Biophys. 55, 138 (1955).

16. Friess, S. L., J. Am. Chem. Soc. 75, 323 (1953).

17. Friess, E. T., Arch. Biochem. Riophys. 51, 17 (1954).

18. Bowen, W. J., And Kerwin, T. D., J. Biol. Chem. 211, 237 (1954).

19. Tonomura, Y., Matsumiya, H., and Kitagawa, S., Biochim. et Biophys. Acta 24, $568(1957)$.

20. Bozler, J. Gen. Physiol. 38, 53 (1954).

21. Greville, G. D., and Reich, E., Biochim. et Biophys. Acta 20, 440 (1956).

22. Tonomura, Y., and Kitagawa, S., Biochim. et Biophys. Acta 27, 15 (1957).

23. Grlmour, D., and Griffiths, M., Arch. Biochem. Biophys. 72, 302 (1057).

24. H.assmlbach, W., Biochim. et Biophys. Acta 20, 355 (1956).

25. Kueluey, W. W., Kalckar, H. M., and Bradley, L. B., J. Biol. Chem. 219, 95 (1956).

26. Morales, M. F., Botts, J., Blum, J. J., And Hilu, T. L., Physiol. Revs. 35, 475 (1955).

27. Ouellet, L., Laidler, K. J., and Morales, M. F., Arch. Biochem. Biophys. 39, 37 (1952).

28. Botts, D. J., And Morales, M. F., Trans. Faraday Soc. 49, 1 (1953).

29. Kielley, W. W., and Bradley, L. B., J. Biol. Chem. 218, 653 (1956).

30. Portzenl, H., Biochim. et Biophys. Acta 14, 195 (1954).

31. Van Eys, J., and Kaplan, N. O., Biochim. et Biophys. Acta 23, 574 (1957). 